\title{
Conference Paper \\ Properties of Tin Monosulphide Films Grown by Chemical Bath Deposition
}

\author{
Gedi Sreedevi and Kotte Tulasi Ramakrishna Reddy \\ Thin Film Laboratory, Department of Physics, Sri Venkateswara University, Tirupati 517 502, India \\ Correspondence should be addressed to Kotte Tulasi Ramakrishna Reddy; ktrkreddy@gmail.com
}

Received 3 January 2013; Accepted 30 April 2013

Academic Editors: P. Agarwal and U. P. Singh

This Conference Paper is based on a presentation given by Gedi Sreedevi at "International Conference on Solar Energy Photovoltaics" held from 19 December 2012 to 21 December 2012 in Bhubaneswar, India.

Copyright (c) 2013 G. Sreedevi and K. Tulasi Ramakrishna Reddy. This is an open access article distributed under the Creative Commons Attribution License, which permits unrestricted use, distribution, and reproduction in any medium, provided the original work is properly cited.

\begin{abstract}
Tin monosulphide $(\mathrm{SnS})$ films have been successfully grown by a simple and low-cost wet chemical process, chemical bath deposition (CBD), using tin chloride and thioacetamide as precursors and tartaric acid as complexing agent. The layers were grown on glass substrate at different bath temperatures $\left(T_{b}\right)$ that varied in the range $50-70^{\circ} \mathrm{C}$. The energy dispersive $\mathrm{X}$-ray analysis (EDAX) studies showed that all the grown films were nearly stoichiometric. The X-ray diffraction analysis indicated that the films had an intense peak at $31.6^{\circ}$ that corresponds to the (111) plane of $\mathrm{SnS}$ and exhibited orthorhombic crystal structure. The intensity of (111) plane increases with the increase in bath temperature and became sharp at $T_{b}=70^{\circ} \mathrm{C}$, where the other crystal planes got suppressed, this indicates better crystallinity of the layers grown at this temperature. No other secondary phases of tin sulphide were observed. The structural parameters such as lattice constants and crystallite size were also calculated. The optical studies revealed that the layers had high optical absorption coefficient $\left(>10^{4} \mathrm{~cm}^{-1}\right)$. The energy band gap was found to be allowed and direct and varied between $1.30 \mathrm{eV}$ and $1.35 \mathrm{eV}$. The band gap decreased with the rise in bath temperature. The refractive index and the extinction coefficient were also evaluated. The details of these results will be presented and discussed.
\end{abstract}

\section{Introduction}

The IV-VI group of semiconductors have a significant role to play in the fabrication of photovoltaic devices [1-7] because of their suitable characteristics like high optical transmittance/ absorbance, energy band gap, and control over electrical properties. Among them, tin monosulphide ( $\mathrm{SnS}$ ) plays a unique role due to its energy band gap of $1.35 \mathrm{eV}$, close to the optimum value of $1.5 \mathrm{eV}$, for maximum absorption of solar radiation. Also, it has high chemical and environmental stability and involves earth abundant elements. Many deposition methods have been reported for the growth of SnS films in the literature [8-15]. However, the development of high quality SnS films by CBD is one of the difficult tasks in the fabrication of SnS based photovoltaic devices and optoelectronic devices. Further, it is crucial to grow the best crystallinity SnS films by CBD without having other impurity phases such as $\mathrm{SnS}_{2}, \mathrm{Sn}_{2} \mathrm{~S}_{3}$, and $\mathrm{SnO}_{2}$ and without any postdeposition chemical/heat treatment processes. In this work, SnS layers were grown by a wet chemical method, chemical bath deposition (CBD), by a simple, economically cheap, nontoxic, and environmentally friendly complexing agent and buffer solution, "tartaric acid," instead of other commonly used reagents because of its dual role in the chemical reaction (complexing agent and $\mathrm{pH}$ value regulator) to minimize experimental difficulties and to get best quality films at different bath temperatures. The properties of these layers were investigated and reported.

\section{Experimental Details}

2.1. Substrate Cleaning. Corning 7059 glass substrates were used in the present study to deposit SnS layers. The substrates were initially washed with "LabClean" solution and rinsed thoroughly with double distilled water. They were immersed in hot chromic acid for 24 hours, rinsed in distilled water, and 


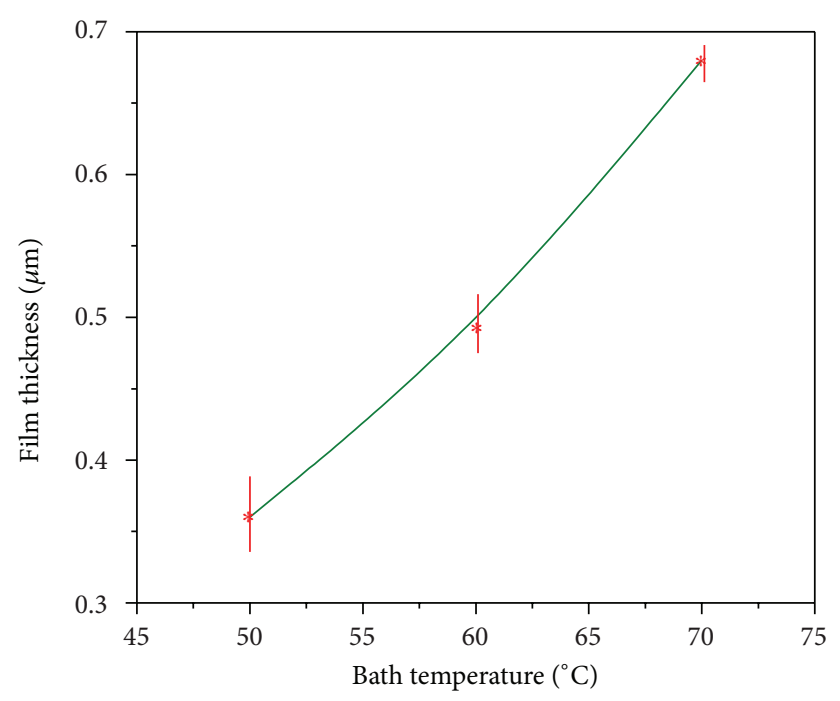

FIGURE 1: Variation in film thickness with the bath temperature.

then cleaned using an ultrasonic vibrator, followed by drying in a hot air oven, before the film deposition.

2.2. Reagents. Analytical grade stannous chloride $\left(\mathrm{SnCl}_{2}\right.$ $\left.\cdot 2 \mathrm{H}_{2} \mathrm{O}\right)$, thioacetamide $\left(\mathrm{C}_{2} \mathrm{H}_{5} \mathrm{NS}\right)$, tartaric acid $\left(\mathrm{C}_{4} \mathrm{H}_{6} \mathrm{O}_{6}\right)$, and concentrated hydrochloric acid $(\mathrm{HCl})$ were used to grow tin monosulphide $(\mathrm{SnS})$ thin films.

2.3. Growth of SnS Films. SnS films were grown using the chemical bath containing tin and sulphur precursors $\left(\mathrm{SnCl}_{2} \cdot 2 \mathrm{H}_{2} \mathrm{O} ; \mathrm{C}_{2} \mathrm{H}_{5} \mathrm{NS}\right)$ at $0.1 \mathrm{M}$ and $0.6 \mathrm{M}$ concentrations, respectively, $1 \mathrm{~mL}$ of tartaric acid, few drops of concentrated $\mathrm{HCl}$, and sufficient quantity of double distilled water to make up $50 \mathrm{~mL}$ of the reaction bath. The $\mathrm{pH}$ of the solution was maintained at 1.5. Tartaric acid is used as complexing agent for the growth of SnS films, and $\mathrm{HCl}$ plays the role of a supporting buffer for the maintenance of constant $\mathrm{pH}$ with the tartaric acid. In the present work, SnS layers were grown at different bath temperatures that vary in the range $50-70^{\circ} \mathrm{C}$ for a constant deposition time of $50 \mathrm{~min}$.

2.4. Characterization of SnS Films. The composition of the elements present in the as-grown films was determined using energy dispersive analysis of X-ray (EDAX) measurement with an Inca Penta X-ray energy analyser attached to the Zeiss scanning electron microscope. The structural properties were carried out using Philips $3003 \mathrm{X}$-ray diffractometer using $\mathrm{Cu}$ $\mathrm{K} \alpha$ radiation in the $2 \theta$ range $10-60^{\circ}$ at a speed of $3^{\circ} / \mathrm{min}$ with a step size of $0.02^{\circ}$. The optical properties were measured using a Hitachi UV-Vis-NIR double beam spectrophotometer and the measurements were recorded in the wavelength range, $300-2500 \mathrm{~nm}$.

\section{Results and Discussion}

The as-grown films appeared to be blackish brown in colour, uniform, pin hole free without any cracks, and well adherent to the substrate surface.

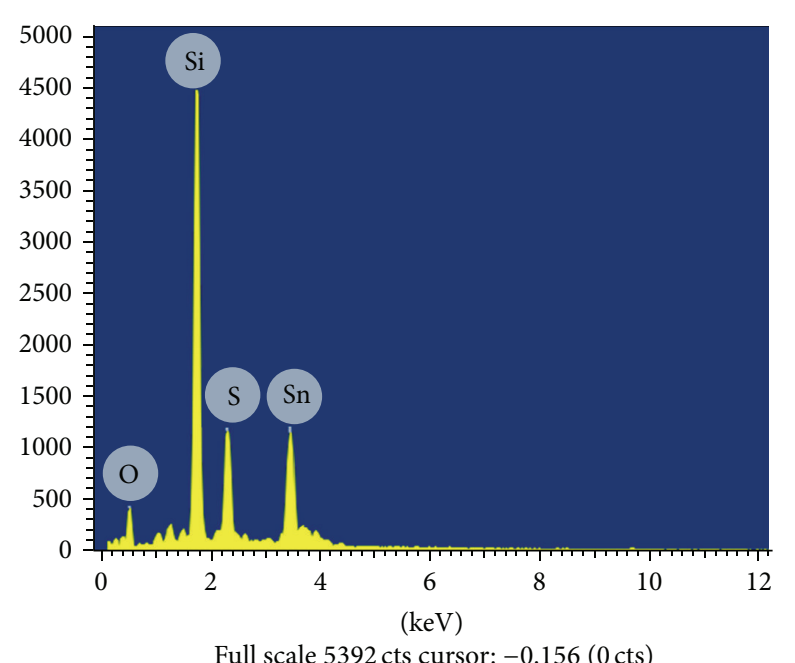

FIgURE 2: EDAX spectrum of an SnS film grown at $T_{b}=70^{\circ} \mathrm{C}$.

3.1. Film Thickness. The film thickness was estimated by the gravimetric method using the formula:

$$
t=\frac{w}{\rho A},
$$

where $w$ is the weight of the film, $A$ is the area of the film and $\rho$ is the density of the material deposited on the substrate. In this work, the density was taken as $5.22 \mathrm{~g} / \mathrm{cm}^{3}$. The films deposited at lower bath temperature were observed to have some small variation in thickness throught the film. However, this variation is marginal at high bath temperature and the films are getting uniform thickness. Figure 1 shows the change of film thickness with bath temperature including with error bars, and it indicated an increase of thickness from $360 \mathrm{~nm}$ to $680 \mathrm{~nm}$ with the rise in the temperature of the chemical bath.

3.2. Elemental Analysis. The composition of as-grown films was estimated from EDAX analysis. The EDAX spectra revealed that all the grown films were nearly stoichiometric and the variation in the elemental composition is marginal. Figure 2 shows the EDAX spectrum of SnS film grown at the bath temperature of $70^{\circ} \mathrm{C}$. The spectrum showed $\mathrm{Sn}$ and $\mathrm{S}$ peaks which confirmed the presence of both the elements in the grown films, and the atomic ratio of $\mathrm{Sn}$ and $\mathrm{S}$ is 49.6 to 50.4. The other peaks observed in the EDAX spectra such as $\mathrm{Si}$ and $\mathrm{O}$ were from glass substrate.

3.3. Structural Behaviour. The X-ray diffraction pattern of the films deposited at different bath temperatures is shown in Figure 3. The analysis indicated that the films had an intense peak at $31.6^{\circ}$ that corresponds to the (111) plane of SnS and exhibited orthorhombic crystal structure (Ref. JCPDS, no. 390354). The other peaks observed at lower bath temperatures correspond to (021), (101), (131), and (121) planes of SnS. The intensity of (111) plane increases with the increase of bath temperature and became sharp at $T_{b}=70^{\circ} \mathrm{C}$, where the other crystal planes got suppressed, indicating that the layers were 


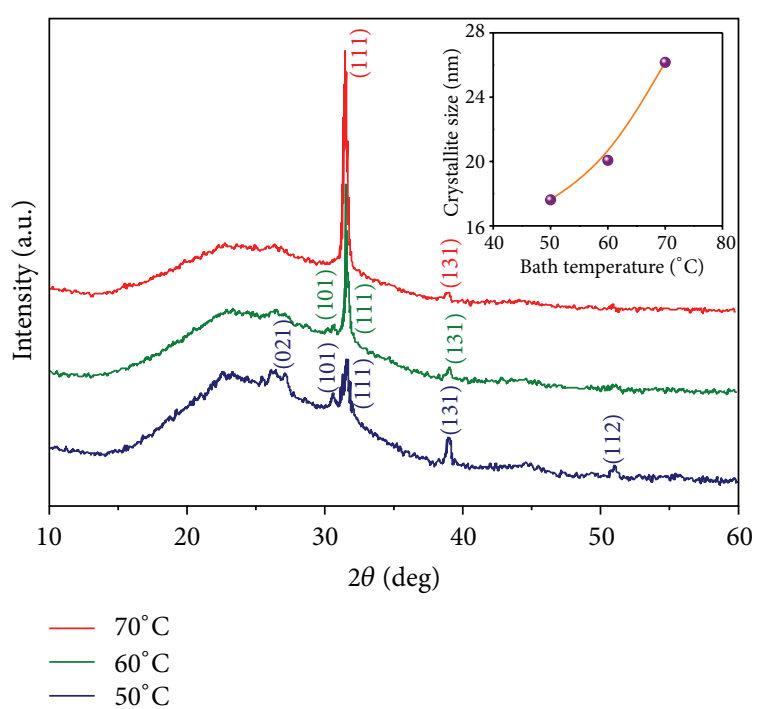

FIgURE 3: XRD profiles of SnS films grown at different bath temperatures (inset). The variation in crystallite size with bath temperature.

highly oriented along the (111) plane. No other secondary phases of tin sulphide such as $\mathrm{SnS}_{2}$ and $\mathrm{Sn}_{2} \mathrm{~S}_{3}$ were observed.

The lattice parameters of the films were calculated using the relation

$$
\frac{1}{d^{2}}=\frac{h^{2}}{a^{2}}+\frac{k^{2}}{b^{2}}+\frac{l^{2}}{c^{2}},
$$

where $h, k, l$ are the Miller indices of the intense peak and $d$ is the interplanar spacing. The evaluated lattice parameters were $a=4.294 \AA, b=11.181 \AA$, and $c=3.962$ using the (111) plane. These values are in good agreement with the reported values [16]. The crystallite size was determined using Scherrer's formula [17]:

$$
D=\frac{k \lambda}{\beta \cos \theta},
$$

where $k$ is a constant representing particle shape factor (0.94), $\lambda$ is the wavelength of the X-rays (1.5418 $\AA$ ), $\beta$ is the full width at half maximum of the (111) peak, and $\theta$ is the corresponding diffraction angle. The inset of Figure 3 shows the variation in crystallite size with bath temperature that indicated an increase from $17 \mathrm{~nm}$ to $27 \mathrm{~nm}$ with the rise in bath temperature.

3.4. Optical Properties. Figure 4 shows the optical transmittance versus wavelength spectra of $\mathrm{SnS}$ films formed at different bath temperatures. All the grown films showed an optical transmittance approximately $60 \%$ above the fundamental absorption edge. The optical absorption coefficient, $\alpha$, was determined using the relation

$$
\ln T=-\alpha t,
$$

where $T$ is the optical transmittance and $t$ is the thickness of the film. The evaluated value of $\alpha$ is found to be $>10^{4} \mathrm{~cm}^{-1}$

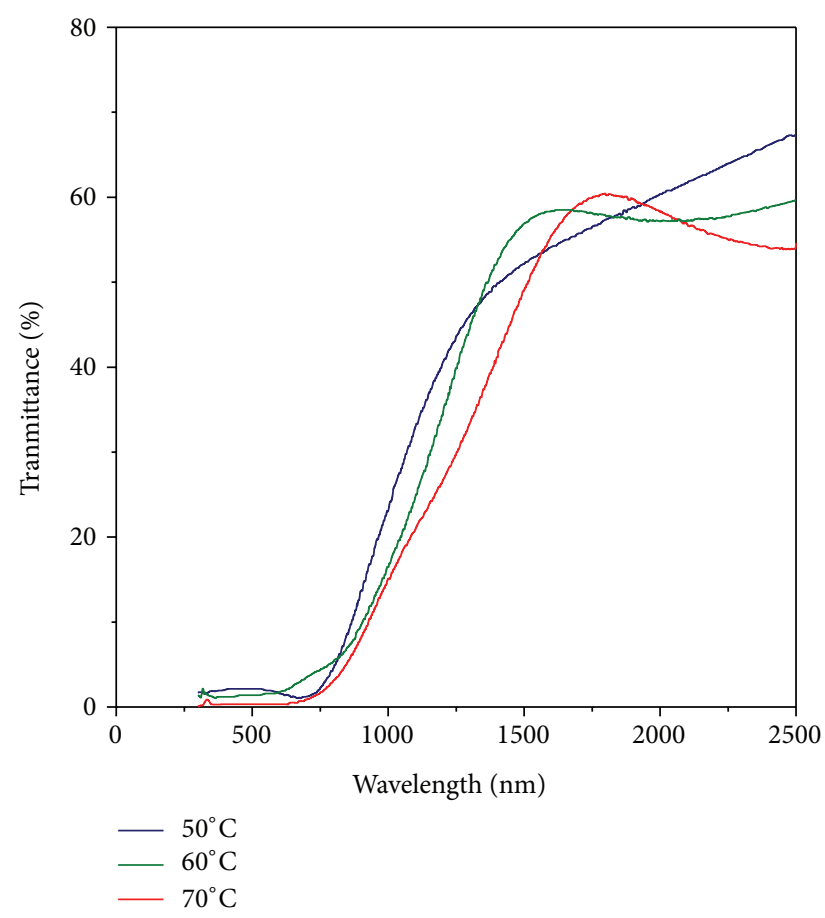

FIGURE 4: Optical transmittance versus wavelength spectra of SnS films grown at different bath temperatures.

in the visible and near infrared regions, indicating that the layers were highly absorbing. This shows that these layers can be useful as an absorber layer for solar cell fabrication.

The optical energy band gap of the films was calculated using the relation

$$
(\alpha h v)=A\left(h v-E_{g}\right)^{1 / 2},
$$

where $A$ is a constant, $h v$ is the photon energy, and $E_{g}$ is the energy band gap of the material. Figure 5 shows the $(\alpha h \nu)^{2}$ versus $h v$ plots, which revealed that the layers had direct allowed energy band gap. The band gap is obtained by extrapolating the $(\alpha h \nu)^{2}$ plot onto the $h v$ axis. The inset in Figure 5 shows the variation in energy band gap with bath temperature where it decreased from $1.35 \mathrm{eV}$ to $1.30 \mathrm{eV}$ with the rise in bath temperature. The observed values of energy band gap in this work were close to the reported data by Nwofe et al. [18] for thermally evaporated SnS layers.

The refractive index $(n)$ and the extinction coefficient values were calculated in the wavelength region $1200-2500 \mathrm{~nm}$ using appropriate formulae,

$$
n^{2}=N+\left(N^{2}-n_{a}^{2} \cdot n_{s}^{2}\right)^{1 / 2}
$$

where

$$
N=\frac{\left(n_{a}^{2}+n_{s}^{2}\right)}{2}+2 n_{a} n_{s} T
$$

Here $n_{a}$ and $n_{s}$ are the refractive indices of air and substrate. One has

$$
k=\frac{\alpha \lambda}{4 \pi}
$$




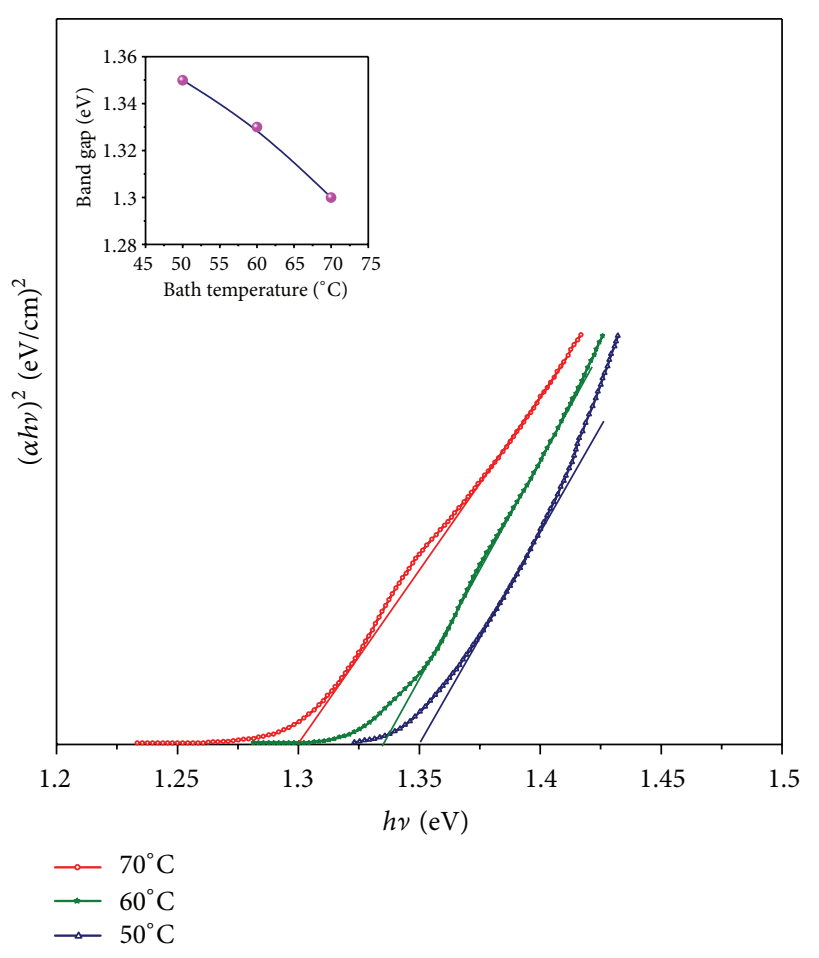

FIGURE 5: $(\alpha h \nu)^{2}$ versus $h v$ plots (inset). The band gap variation with bath temperature.

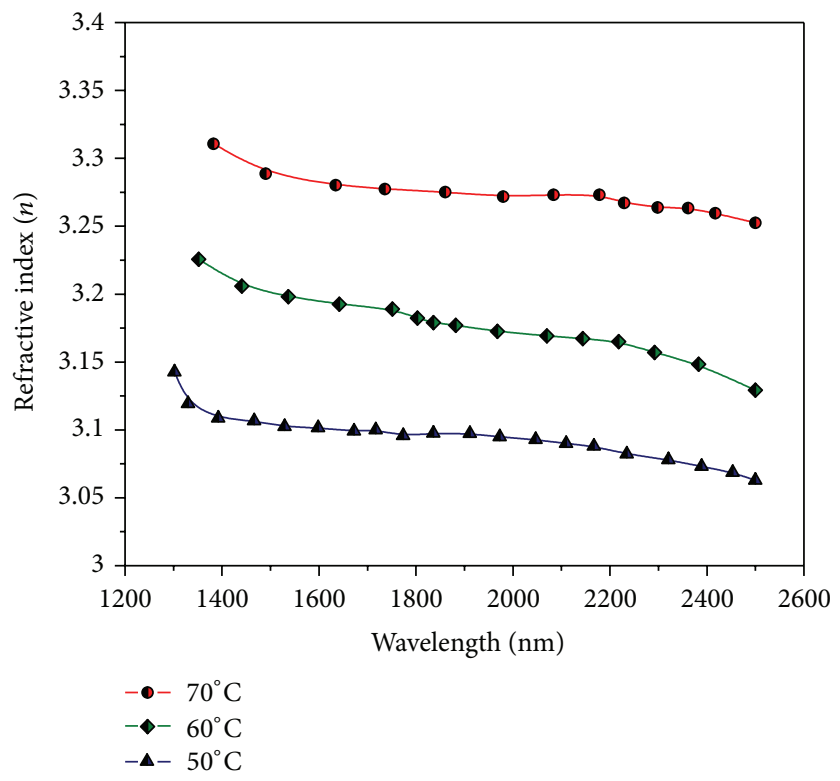

FIGURE 6: Variation in refractive index with wavelength of the SnS films with bath temperature.

where $\alpha, \lambda$ are the absorption coefficient and wavelength. The variations in $n$ and $k$ with wavelength are shown in Figures 6 and 7. The refractive index varied in the range 3.1-3.3 whereas the extinction coefficient changed from 0.03 to 0.1 as observed by other works in the literature [19-21].

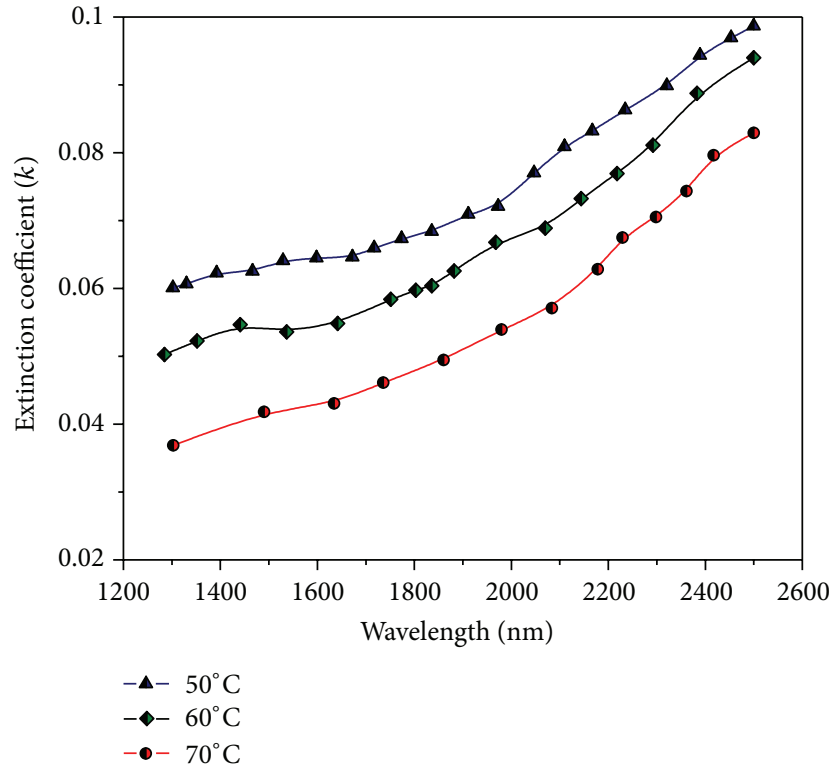

Figure 7: Change of extinction coefficient of the SnS films with bath temperature.

\section{Conclusions}

Tin monosulphide films (SnS) were grown by a simple chemical bath deposition technique on glass substrates at different bath temperatures that varied in the range $50-70^{\circ} \mathrm{C}$. All the films showed the (111) plane as the dominant orientation. Although the layers formed at lower bath temperatures had shown the presence of other crystal planes in addition to (111), they were suppressed subsequently with the rise in bath temperature to $70^{\circ} \mathrm{C}$. The layers had an optical absorption coefficient $>10^{4} \mathrm{~cm}^{-1}$ in the visible and near infrared region, and the evaluated energy band gap varied in the range 1.30$1.35 \mathrm{eV}$. The refractive index and extinction coefficient values were also evaluated they showed the usual trend.

\section{Acknowledgments}

The authors would like to thank Professor R. W. Miles and Mr. P. A. Nwofe, School of Engineering and Environment, Northumbria University, Newcastle, UK, for the XRD analysis of the samples.

\section{References}

[1] K. T. Ramakrishna Reddy, P. Prathap, and R. W. Miles, "Thin films of tin sulphide for application in photovoltaic solar cells," in Photovoltaics: Developments, Applications and Impact, $\mathrm{H}$. Tanaka and K. Yamashita, Eds., pp. 1-27, Nova Science, New York, NY, USA, 2010.

[2] K. T. Ramakrishna Reddy, N. Koteswara Reddy, and R. W. Miles, "Photovoltaic properties of SnS based solar cells," Solar Energy Materials and Solar Cells, vol. 90, no. 18-19, pp. 3041-3046, 2006.

[3] S. A. Bashkirov, V. F. Gremenok, V. A. Ivanov, V. V. Lazenka, and K. Bente, "Tin sulfide thin films and Mo/p-SnS/n-CdS/ZnO 
heterojunctions for photovoltaic applications," Thin Solid Films, vol. 520, pp. 5807-5810, 2012.

[4] N. R. Mathews, "Electrodeposited tin selenide thin films for photovoltaic applications," Solar Energy, vol. 86, pp. 1010-1016, 2012.

[5] M. Tessema and M. Giolando, "Pinhole treatment of a CdTe photovoltaic device by electrochemical polymerization technique," Solar Energy Materials and Solar Cells, vol. 107, pp. 9-12, 2012.

[6] J. Yoon, S. Jo, I. S. Chun et al., "GaAs photovoltaics and optoelectronics using releasable multilayer epitaxial assemblies," Nature, vol. 465, no. 7296, pp. 329-333, 2010.

[7] A. Rockett and R. W. Birkmire, "CuInSe 2 for photovoltaic applications," Journal of Applied Physics, vol. 70, pp. R81-R97, 1991.

[8] P. A. Nwofe, K. T. Ramakrishna Reddy, J. K. Tan, I. Forbes, and R. W. Miles, "Thickness dependent optical properties of thermally evaporated SnS thin films," Physics Procedia, vol. 25, pp. 150-157, 2012.

[9] M. Devika, K. T. Ramakrishna Reddy, N. Koteeswara Reddy et al., "Microstructure dependent physical properties of evaporated tin sulfide films," Journal of Applied Physics, vol. 100, Article ID 023518, 7 pages, 2006.

[10] K. T. Ramakrishna Reddy, P. Purandar Reddy, R. W. Miles, and P. K. Datta, "Investigations on $\mathrm{SnS}$ films deposited by spray pyrolysis," Optical Materials, vol. 17, no. 1-2, pp. 295-298, 2001.

[11] T. H. Sajeesh, K. B. Jinesh, C. Sudha Kartha, and K. P. Vijayakumar, "Role of $\mathrm{pH}$ of precursor solution in taming the material properties of spray pyrolysed SnS thin films," Applied Surface Science, vol. 258, pp. 6870-6875, 2012.

[12] B. Thangaraju and P. Kaliannan, "Spray pyrolytic deposition and characterization of SnS and SnS2 thin films," Journal of Physics D, vol. 33, no. 9, pp. 1054-1059, 2000.

[13] L. L. Cheng, M. H. Liu, M. X. Wang et al., "Preparation of SnS films using solid sources deposited by the PECVD method With controllable film characters," Journal of Alloys and Compounds, vol. 545, pp. 122-129, 2012.

[14] R. Mariappan, T. Mahalingam, and V. Ponnuswamy, "Preparation and characterization of electrodeposited SnS thin films," Optik, vol. 122, pp. 2216-2219, 2011.

[15] F. Jiang, H. Shen, C. Gao, B. Liu, L. Lin, and Z. Shen, "Preparation and properties of SnS film grown by two-stage process," Applied Surface Science, vol. 257, no. 11, pp. 4901-4905, 2011.

[16] G. H. Yue, L. S. Wang, X. Wang, Y. Z. Chen, and D. L. Peng, "Characterization and optical properties of the single crystalline SnS nanowire arrays," Nanoscale Research Letters, vol. 4, no. 4, pp. 359-363, 2009.

[17] B. E. Warren, X-Ray Diffraction, Dover, New York, NY, USA, 2nd edition, 1990.

[18] P. A. Nwofe, K. T. Ramakrishna Reddy, G. Sreedevi, J. K. Tan, and R. W. Miles, "Structural, optical, and electro-optical properties of thermally evaporated tin sulphide layers," Japanese Journal of Applied Physics, vol. 51, Article ID 10NC36, 2012.

[19] M. Devika, N. K. Reddy, K. Ramesh, K. R. Gunasekhar, E. S. R. Gopal, and K. T. R. Reddy, "Influence of annealing on physical properties of evaporated SnS films," Semiconductor Science and Technology, vol. 21, no. 8, pp. 1125-1131, 2006.

[20] E. Turan, E. Kul, A. S. Aybek, and M. Zor, "Structural and optical properties of SnS semiconductor films produced by chemical bath deposition," Journal of Physics D, vol. 42, no. 24, Article ID 245408, 2009.
[21] M. S. Selim, M. E. Gouda, M. G. El-Shaarawy, A. M. Salem, and W. A. Abd El-Ghany, "Effect of thickness on optical properties of thermally evaporated SnS films," Journal of Applied Sciences Research, vol. 7, pp. 955-961, 2011. 

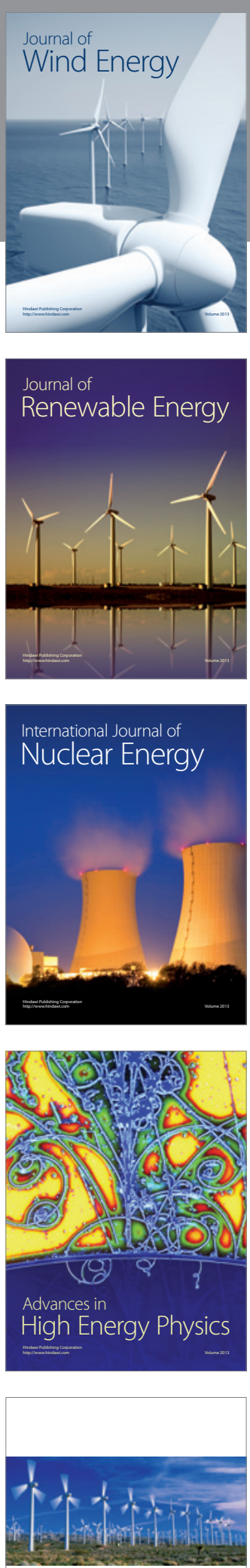

ISRN

Renewable Energy
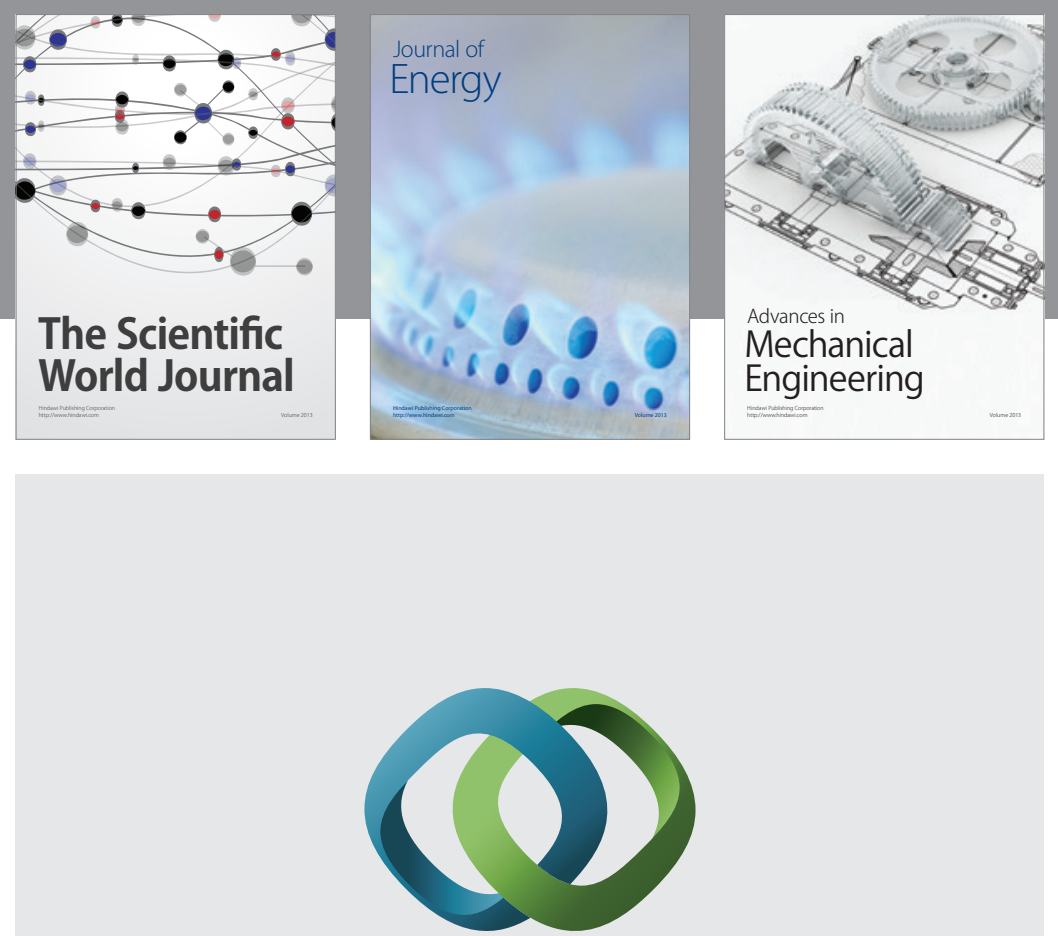

\section{Hindawi}

Submit your manuscripts at http://www.hindawi.com
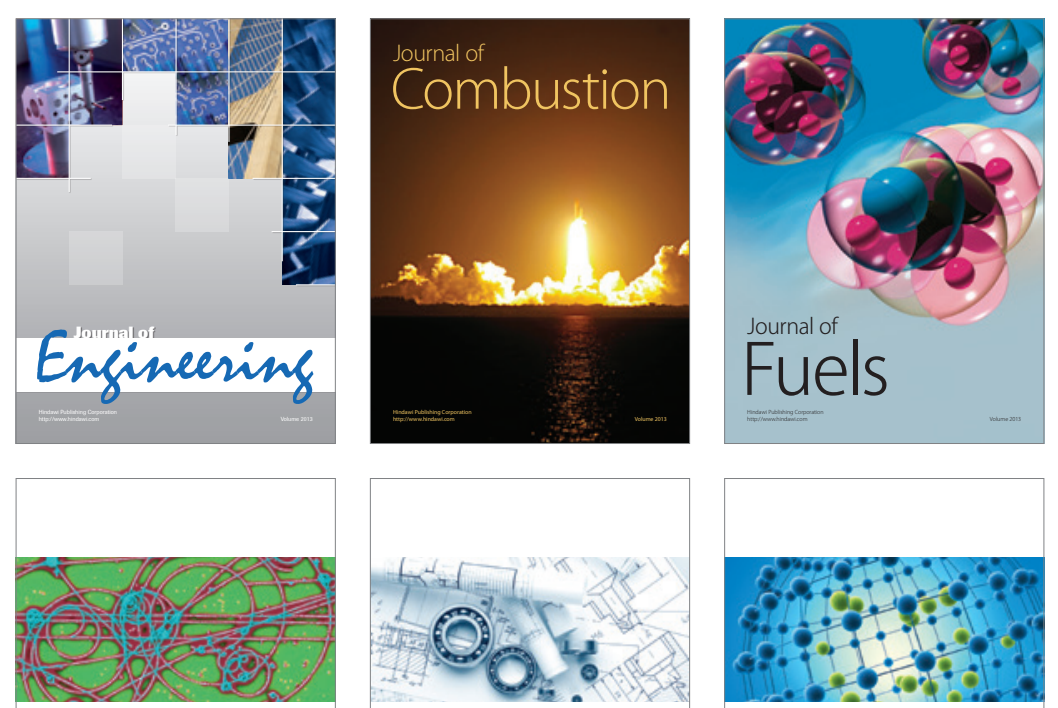

ISRN

High Energy Physics

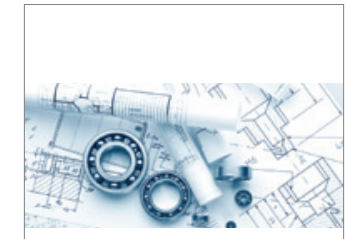

ISRN

Mechanical

Engineering

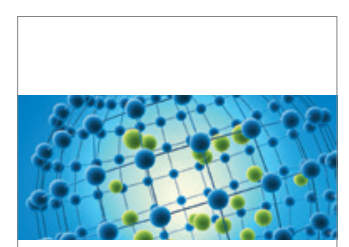

ISRN

Chemical

Engineering
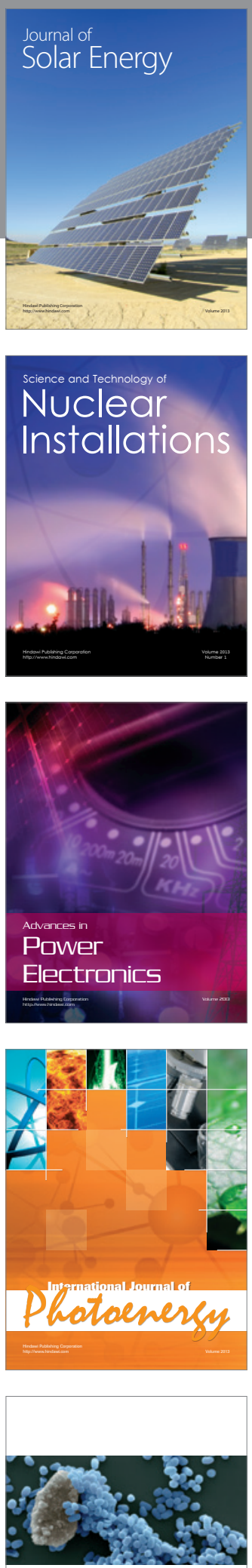

ISRN

Biotechnology 

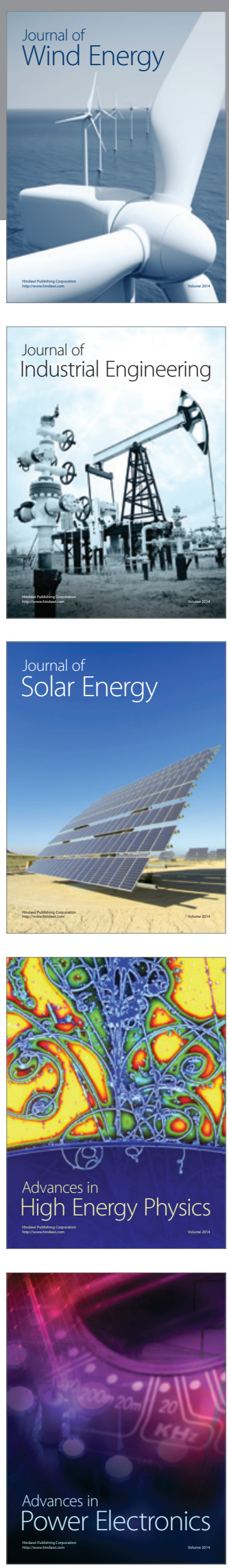
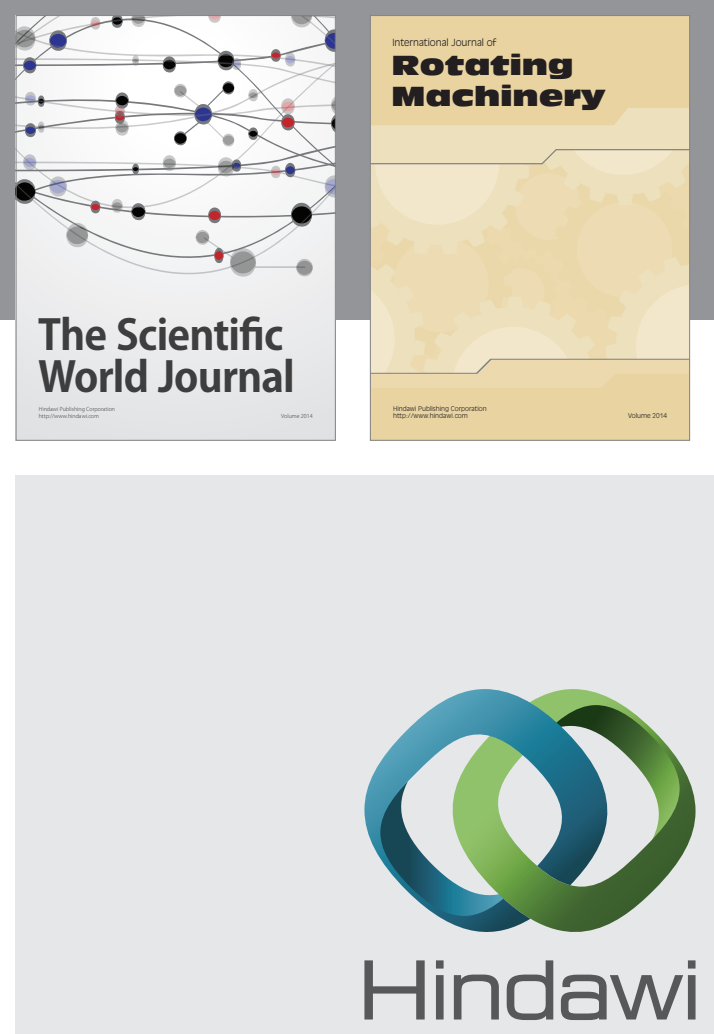

Submit your manuscripts at

http://www.hindawi.com
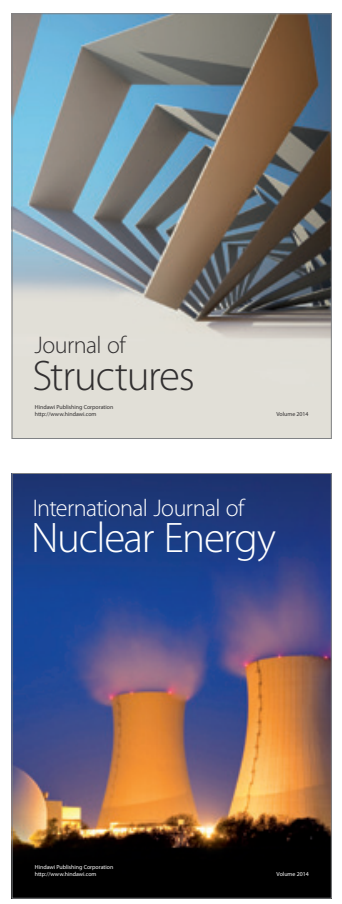
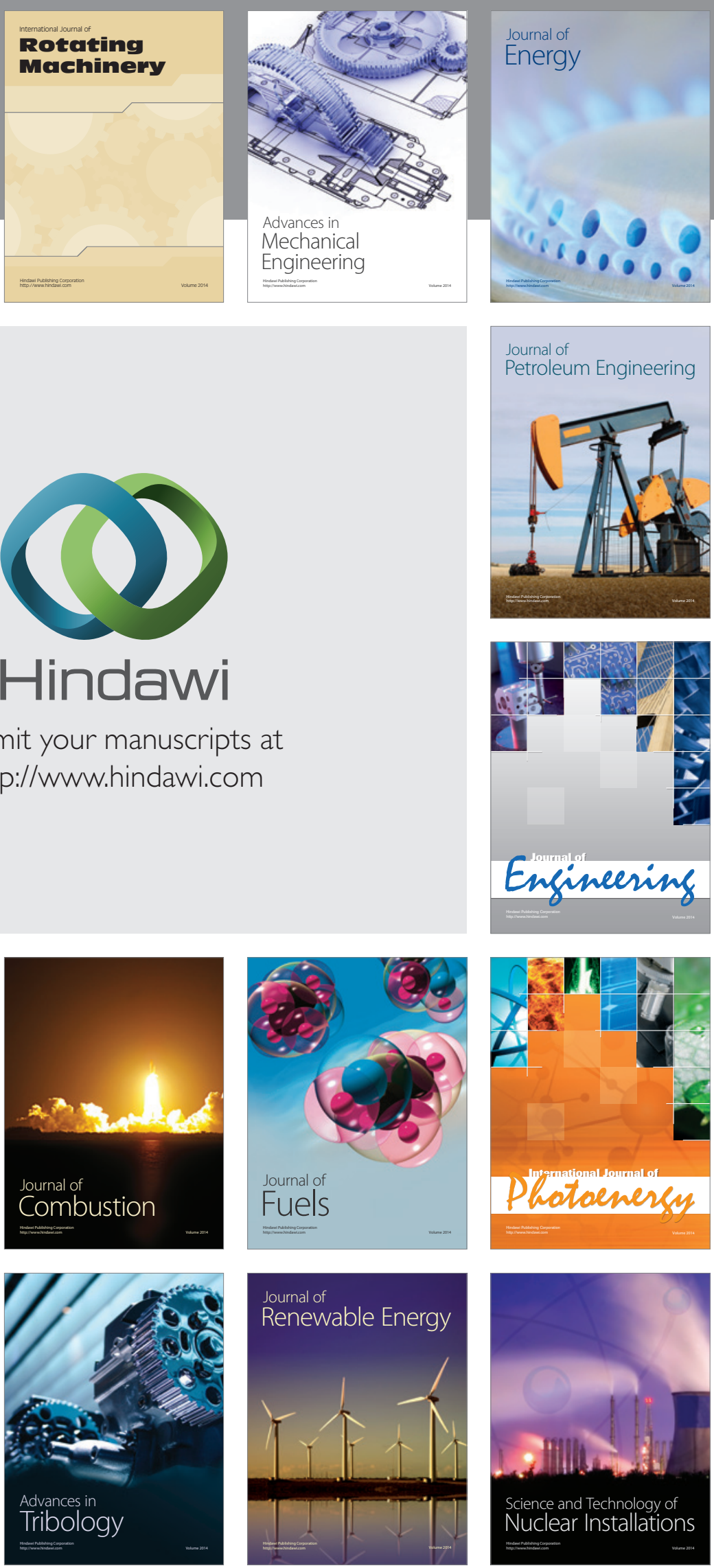